\title{
Análise da distribuição de água na bacia do Rio Apeú através do modelo SWAT
}

A disponibilidade hídrica de uma bacia hidrográfica depende da variabilidade temporal e espacial expressa por várias funções hidrológicas, as quais são influenciadas pelo clima, fisiografia e uso de solo. Este artigo se propôs avaliar espacialmente a distribuição de água na bacia do rio Apeú, através da simulação da produção de água (WYLD) gerada pelo modelo SWAT, durante o período de 2007 a agosto de 2018. Para isso, utilizou-se o modelo SWAT na simulação de diversas informações que compõem o balanço hídrico, em especial a produção de água, a partir de informações de uso e tipo de solo, declividade e dados climáticos obtidos de órgão como o Instituto Brasileiro de Geografia e Estatística (IBGE), o Instituto Nacional de Pesquisas Espaciais (INPE) e o Instituto Nacional de Meteorologia (INMET), bem como, características morfométricas calculadas a partir do Sistema de Informações Geográficas (SIG). Os resultados demonstraram que a WYLD está intimamente ligada com a dinâmica dos usos e ocupações do solo e a morfometria da bacia do rio Apeú, ao longo dos anos analisados, e não somente a sazonalidade das precipitações na região. Ainda, em decorrência das mudanças sofridas pela bacia ocasionaram um aumento em cerca de $30 \%$ das perdas de água e diminuíram em até $60 \%$ a sua produção o que pode ser prejudicial à população que dependem da bacia, para a pesca, transporte, entre outros.

\section{Analysis of water distribution in the Apeú River basin through the SWAT model}

\begin{abstract}
The water availability of a river basin depends on the temporal and spatial variability expressed by several hydrological functions, which are influenced by climate, physiography and soil use. This paper proposes to spatially evaluate the water distribution in the Apeú river basin, through the simulation of water production (WYLD) generated by the SWAT model, during the period from 2007 to August 2018. For this purpose, the SWAT model for the simulation of diverse information that compose the water balance, especially the water production, from information of use and type of soil, slope and climatic data obtained from organ such as IBGE, INPE and INMET, as well as calculated morphometric characteristics from the Geographic Information System. The results showed that WYLD is closely linked to the dynamics of soil uses and occupations and morphometry of the Apeú river basin over the years analyzed, not only the seasonality of rainfall in the region. Still, these results showed that as a result of these changes suffered by the basin caused an increase in about $30 \%$ of the water losses and reduced their production by up to $60 \%$, which may be detrimental to the population that depend on the basin.
\end{abstract}

Keywords: Hydrological modeling; Water availability and GIS.

Joyse Tatiane Souza dos Santos (iD Universidade Federal do Pará, Brasil http://lattes.cnpq.br/2036384240460046 http://orcid.org/0000-0001-7292-8738 joysetaty@hotmail.com

Hildo Giuseppe Garcia Caldas Nunes (iD) Universidade Federal Rural da Amazônia, Brasil http://lattes.cnpq.br/5534561793631040 http://orcid.org/0000-0003-4072-003X garibalde13@gmail.com

\section{Amanda Gama Rosa (i)}

Universidade Federal do Pará, Brasil http://lattes.cnpq.br/0895837333331224 http://orcid.org/0000-0002-9053-2777 amandagamarosa@hotmail.com

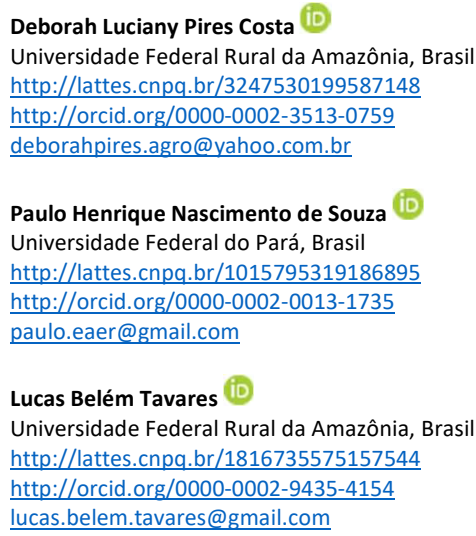

Adriano Marlisom Leão de Sousa (it) Universidade Federal Rural da Amazônia, Brasil http://lattes.cnpq.br/4371199443425884 http://orcid.org/0000-0002-2809-5318 marlisoms@yahoo.com.br

\section{Referencing this:}

SANTOS, J. T. S.; NUNES, H. G. G. C.; ROSA, A. G.; COSTA, D. L. P.; SOUZA, P. H. N.; TAVARES, L. B.; SOUSA, A. M. L.. Análise da distribuição de água na bacia do Rio Apeú através do modelo SWAT. Revista Ibero Americana de Ciências Ambientais, v.10, n.3, p.368384, 2019. DOI: http://doi.org/10.6008/CBPC21796858.2019 .003 .0031

DOI: 10.6008/CBPC2179-6858.2019.003.0031 


\section{INTRODUÇÃO}

A água é indispensável à manutenção da vida em todo o planeta, isso a torna insubstituível para todas as atividades humanas. Já os impactos causados pelo homem ao ambiente natural vêm ao longo dos anos, dificultando a sua utilização de forma sustentável, e consequentemente diminuindo sua disponibilidade (OLIVEIRA et al., 2015). Apesar de sua importância, as formas de obter informações sobre o ciclo hidrológico ainda são bastante limitadas, principalmente em escalas de bacias, tornando difíceis as obtenções de informações que auxiliem no entendimento dos principais componentes do balanço hidrológico, como a evaporação, a condensação e os escoamentos (BARRY et al., 2013).

Todos estes processos além de auxiliar no entendimento deste balanço em uma bacia hidrográfica, também ajudam a identificar as condições de excedente ou de deficiência de água (ABREU et al., 2015), contudo, elas sofrem alterações significativas em decorrência de atividades antrópicas, como as modificações na ocupação da terra, o desmatamento, a expansão da agropecuária e a urbanização (COUTINHO et al., 2013).

Santos et al. (2007) e Doriguel et al. (2015) acreditam que para avaliar o possível efeito de qualquer perturbação numa bacia hidrográfica, é necessário conhecer, inicialmente, as características do ecossistema em suas condições naturais de equilíbrio, a fim de estabelecer comparações entre as condições hidrológicas e de qualidade da água no ecossistema natural e os ecossistemas nos quais ocorre ação direta do homem.

Para Usace (2010) e Correia et al. (2015), as técnicas avançadas de modelagem hidrológica tornaramse viáveis, porque agora a geração e manipulação de dados podem ser feitas com eficiência por meio de operações espaciais em um Sistema de Informações Geográficas (SIG), não só economizando tempo e esforço, como também, melhorando a precisão em relação aos métodos tradicionais.

Desta forma, um modelo hidrológico pode estimar as dinâmicas hidrológicas, através de equações que caracterizam o comportamento hidrológico de uma bacia (ALMEIDA et al., 2017). Eles possuem diversas tipologias, podendo também se distinguir conforme o objetivo da simulação (MORIASI, 2015). Entre os atuais modelos existentes, se destaca o Soil and Water Assessment Tool (SWAT) (ARNOLD et al., 1998; ARNOLD et al., 2005; GASSMAN et al., 2007), que tem sido amplamente utilizado em estudos de bacias no Brasil (BRESSIANI et al., 2015; BLAINSKI et al., 2017; SILVA et al., 2017; SANTOS et al., 2018) e também, devido a sua flexibilidade e aplicações voltadas para o monitoramento de vazões, projeções de enchentes, qualidade da água, processos erosivos eentre outros (TESHAGER, 2016).

O modelo SWAT permite simular a produção de água em bacias hidrográficas, em nível da própria bacia, sub-bacia ou unidades de respostas, onde a quantidade de água produzida é igual à soma entre, a contribuição do escoamento superficial, do escoamento lateral, do escoamento subterrâneo, menos as perdas de transmissão em canais tributários ou por percolação na sub-bacia. Ela pode ser definida como a quantidade de água que efetivamente contribui para a vazão no canal durante um intervalo de tempo (ARNOLD et al., 2012).

O artigo se concentrou em avaliar espacialmente a distribuição de água na bacia do rio Apeú, através 
da simulação da produção de água (WYLD) gerada pelo modelo SWAT, durante o período de 2007 a agosto de 2018. Com isso verificar neste período, os acontecimentos positivos e negativos provocados pela ocupação inadequada de encostas e margens dos afluentes e como isso pode estar implicando na vida útil da bacia, bem como, se há condições favoráveis para que a população possa usufruir de forma saudável e preservando as nascentes.

O uso da modelagem aplicado aos processos que envolvem a relação precipitação - vazão em uma bacia hidrográfica nos pressupõe o conhecimento de todos os componentes (precipitação, interceptação, evapotranspiração, infiltração, percolação, armazenamento da água no solo e superfície) que atuam no ciclo hidrológico, sendo responsáveis pelos deflúvios da bacia, o qual é influenciado por três grandes grupos de fatores: clima, fisiografia e uso de solo. Ainda, o clima pode afetar tanto a distribuição espacial e temporal das variáveis hidrológicas (chuva e vazão), quanto à intensidade e frequência de eventos extremos. Enquanto que o uso do solo e a fisiografia influenciam diretamente na velocidade de escoamento da água em direção ao rio principal, alterando a quantidade de água escoada (ADAM et al., 2015).

A principal entrada da água na sub-bacia é através da precipitação, devido ao fato desta controlar o balanço de água, se tornando de suma importância que a quantidade e a distribuição no tempo e no espaço sejam simuladas com exatidão no modelo, já que todos os outros processos iram depender dela, como o tempo de concentração, em que a partir do início de uma chuva (evento pluviométrico) até que a área inteira da sub-bacia esteja contribuindo para o fluxo na saída (NEITSCH et al., 2009).

\section{REVISÃO TEÓRICA}

\section{Estudo Hidrológico e a sua Importância na Distribuição de Água na Vila Apeú}

As bacias hidrográficas possuem uma área de captação natural da água (precipitação) que faz convergir o escoamento para um único ponto de saída. Então pode ser considerado um ente sistêmico. É onde acontecem os balanços de água, pela entrada proveniente da chuva e de saída através do exultório, permitindo que sejam delineadas bacias e sub-bacias, cujas interconexões se dão pelos sistemas hídricos (PORTO et al., 2008; DORIGUEL et al., 2015).

Tucci (2009) considera a hidrologia como sendo uma ciência interdisciplinar em evolução diante dos crescentes problemas, devido à ocupação das bacias, da demanda pela utilização da água e o impacto sobre o meio ambiente, que passou de uma ciência preponderantemente descritiva e qualitativa, para uma área do conhecimento na qual os métodos quantitativos são explorados por meio de modelos matemáticos e estatísticos, melhorando os resultados e a previsão de ocorrência de inundações (CORREIA et al., 2015).

Marinho Filho et al. (2012) compreendem que os processos hidrológicos são fundamentais para estudos dos recursos hídricos, em que o tempo que a água permanece nas diversas partes da hidrosfera influência, entre outros, a disponibilidade hídrica, a ocorrência de inundações e a dinâmica de elementos, nutrientes e poluentes.

De acordo com Rodrigues et al. (2013) a água é uma fonte natural classificada como renovável finita 
e aleatória, sendo essencial para vida humana. Por sua capacidade de se recompor rapidamente, em quantidade, principalmente pelas chuvas, ela é renovável, mas é considerado um recurso finito, pois pode ser comprometida facilmente pela poluição, tornando-se inadequada para o uso humano. É de ocorrência aleatória, pois sua distribuição é irregular no tempo e por região, sendo influenciada pelas condições climáticas e meteorológicas.

Sabendo que a água é um recurso essencial para a vida humana e com a possibilidade de sua escassez, a Lei de Política Nacional de Recursos Hídricos (Lei n.9433/97) considerou a água um bem econômico que abrange diferentes fontes para sua utilização. Essas fontes, denominadas de Recursos Hídricos, são compostas por águas superficiais (rios, lagos, lagoa se bacias e mar territorial) e subterrâneas (BARROS et al., 2009; RODRIGUES et al., 2013).

O rio Apeú possui um comprimento de aproximadamente de $27,87 \mathrm{~km}$, e na sua extensão estão os municípios de Castanhal, Santa Izabel do Pará e Inhangapi, possuindo como principais afluentes, os igarapés Macapazinho, Castanhal, Americano, Quatro, Praquiquara, Apeteua, Janjão, Fonte Boa, Marapanim, Taiteua, Papuquara, Capiranga, Itaqui e São João. Ao longo de sua influência encontram-se diversas localidades (vilarejos, povoados, fazendas, etc.), sendo a maior concentração na porção norte e central da bacia. Possui características de atividades rurais e urbanas, apresentando diversos usos no seu território, dentre estes se destacam: a agricultura, a pecuária e a extração mineral. Atualmente, a expansão da urbanização com os loteamentos residenciais tem contribuído com os demais usos no processo de transformação da paisagem (VALE et al., 2015).

Mantê-la é de suma importância para a boa qualidade de vida dos seres vivos, ela possui funções ambientais importantes tanto para a natureza quanto para a população que dependem dela, seja para subsistência ou lazer (PANIZZA, 2016). Contudo a crescente demanda por água para usos domésticos, industriais e agrícolas, os cursos fluviais tem sofrido agressões e por conta disso poucos ainda mantêm suas condições naturais preservadas (VARGAS et al., 2012).

Montaño et al. (2016) descrevem a disponibilidade hídrica, tanto em termos de quantidade quanto em termos de qualidade e tempo de recorrência, um fator relevante ao desenvolvimento econômico e social de uma bacia hidrográfica, existe a necessidade de se voltar à atenção do planejamento para a sustentabilidade dos recursos hídricos, atuando principalmente de forma preventiva sobre a gestão da demanda.

A definição adotada para a disponibilidade hídrica foi dada por Cruz et al. (2008) que a define como a parcela de vazão que pode ser utilizada pela sociedade para o seu desenvolvimento, sem comprometer o meio ambiente aquático. De outro lado a vazão resultante no rio após o uso da água é denominada aqui de vazão remanescente ('instreamflow', segundo a literatura inglesa de Kramer). Esta vazão tem a finalidade de manter a integridade do sistema fluvial conservando o meio ambiente aquático.

Ainda segundo os autores a disponibilidade hídrica tem condicionantes de variabilidade no tempo e no espaço e não está limitada ao uso consultivo, mas também às alterações que pode produzir no hidrograma do rio em relação às condições pré-existentes. Estes condicionantes possuem restrições quantitativas e 
qualitativas estabelecidas tanto para atender os diferentes usos ao longo do tempo e do espaço, quanto para manter a integridade ambiental.

\section{MATERIAIS E MÉTODOS}

\section{Área de estudo}

A bacia do Rio Apeú situa-se na mesorregião metropolitana de Belém, no estado do Pará. Ela possui seu exultório no rio Inhangapi, que juntos somam-se ao conjunto de sub-bacias que contribuem com rio Guamá, totalizando uma área de aproximadamente $307 \mathrm{~km}^{2}$. O clima predominante na região é do tipo Ami, de acordo com a classificação de Koppen, com precipitação média anual em torno de 2571,6 mm. A distribuição de chuva na região é definida pelo período chuvoso, que vai de janeiro a abril e menos chuvoso que se estende de agosto a novembro. A temperatura média anual é de $26^{\circ} \mathrm{C}$, com mínimas de $18^{\circ} \mathrm{C}$ e máximas de $35^{\circ} \mathrm{C}(\mathrm{SOUZA}, 2017)$.

\section{Dados obtidos}

Para aplicação do modelo SWAT, estruturou-se um banco de dados, contendo informações sobre o tipo e uso do solo, declividade e dados climáticos diário hidrológicos. Os dados climáticos (Temperatura máxima e mínima, velocidade do vento, precipitação, umidade relativa e radiação solar) foram obtidos da estação automática meteorológica, do Instituto Nacional de Meteorologia (INMET) em Castanhal/PA, no período de 2007 a agosto de 2018, e a vazão através do método convencional, com a utilização do molinete hidrométrico, para a determinação da área e da velocidade média do fluxo que passa pela seção transversal do ponto monitorado (MALDONADO et al., 2015). Estes fluxos foram medidos em três seções $(0,5 \mathrm{~m}, 1 \mathrm{~m}$ e $1,5 \mathrm{~m})$, ao longo do comprimento total $(2,20 \mathrm{~m})$ da seção transversal do tributário do rio Apeú, em nível d'água de $0,14,0,14$ e $0,11 \mathrm{~m}$ ( $60 \%$ de profundidade), durante um ano (de outubro a dezembro de 2017 e janeiro a agosto de 2018), conforme resolução da ISO 748 (ISO, 2007), para maiores detalhes sobre a metodologia e os valores obtidos ver em Santos et al. (2018).

A informação base para definição das unidades espaciais no modelo SWAT é dada através do modelo numérico do terreno (MNT), que foi obtido do site da Empresa Brasileira de Pesquisa Agropecuária (EMBRAPA), a partir de imagens SRTM, com resolução espacial de $90 \mathrm{~m}$. Posteriormente foi transformada em imagens raster, de resolução espacial de $30 \mathrm{~m}$, na escala de 1: 250.000, assim como todas as imagens e informações utilizadas neste estudo.

O modelo ainda requer os mapas de tipos e uso do solo, onde as informações de uso do solo foram elaborados com base no projeto TerraClass desenvolvido pelo Instituto Nacional de Pesquisas Espaciais (INPE) (ALMEIDA et al., 2016), a partir de imagens LANDSAT-5, na órbita/ponto 223/061, que foram organizadas de acordo com o banco de dados do SWAT, gerando seis classes, distribuídas em: Áreas antrópicas Agrícolas, Áreas Urbanas, Pastagens, Floresta Mista, Mineração e os corpos hídricos (Santos et al., 2018). Os tipos de solos foram obtidos a partir do banco de dados do Instituto Brasileiro de Geografia e 
Estatística (IBGE), sendo encontrados dois tipos: Latossolo amarelo e Gleissolo Háplico. Maiores detalhes sobre as informações e bancos de dados necessários para entrada no modelo se encontram em Perazzoli et al. (2013).

\section{Validação do modelo}

Os dados foram processados no software ArcGIS 10.3, através da extensão ArcSWAT 2012 (versão 10_2.15) (WINCHELL et al., 2013). A calibração do SWAT foi realizada através do programa SWAT-CUP 2012 (versão 5.1.6.2), adotando o algoritmo de calibração SUFI2. Detalhamentos sobre o desenvolvimento dos dados e os demais processos (calibração e analises estatísticas) podem ser vistos em Santos et al. (2018).

A simulação hidrológica foi desenvolvida, no período de 2007 a setembro de 2018, sendo comparados os valores de vazão simulados com os valores de vazões observados (etapa de calibração), para o período de outubro de 2017 a março de 2018, enquanto a etapa de validação ocorreu no período de janeiro a agosto de 2018. Para que coincidissem os pontos de medição da velocidade da água com os pontos de saída, a sub-bacia 10 foi utilizada para a comparação da vazão simulada pelo modelo.

Para determinar quais as variáveis são mais sensíveis e importantes para o escoamento, foram analisados quinze parâmetros durante a calibração. Nesta etapa, foram realizadas 2 iterações, padronizadas com 500 simulações cada, até a obtenção de um intervalo (valores mínimos e máximos) adequado às condições da bacia (ABBASPOUR, 2015).

Os parâmetros mais sensíveis e que possuem maiores influências na modelagem da vazão, na bacia do Rio Apeú, durante esta etapa foram: Coeficiente de rugosidade do canal principal (CN2); fator do Fluxo de base (ALPHA_BF); intervalo de tempo para a recarga do aquífero (GW_DELAY); percolação para o aquífero profundo (REVAPMN); profundidade inicial de água no aquífero profundo (DEEPST); nível limite de água no aquífero livre para ocorrer o fluxo de retorno (GWQMN); Armazenamento de água no solo (SOL_AWC); Coeficiente de compensação de evaporação de água no solo (ESCO); Coeficiente de ascensão de água à zona de saturação (GW_REVAP); Coeficiente de percolação da água para o aquífero profundo (RCHRG_DP); Coeficiente de retardamento do escoamento superficial direto (SURLAG); Coeficiente de Manning para o canal principal (CH_N2); Comprimento da declividade para o escoamento subsuperficial (SLSOIL); escoamento lateral (LAT_TTIME) e água interceptada (CANMX).

O desempenho do modelo é obtido na comparação entre os valores observados e simulados, calculados com base nos seguintes métodos estatísticos: o coeficiente de eficiência de Nash-Sutcliffe ( $\mathrm{NS}_{\mathrm{Ef}}$ ) (NASH et al., 1970) (que varia do $\infty$ até 1), o coeficiente de determinação $R^{2}$ (que varia de 0 a 1), e o PBIAS (Erro Sistemático Bias) (\%), que avalia a tendência média dos valores simulados serem maiores (subestimativa) ou menores (superestimativa) do que os observados, sendo o seu valor ideal próximo e/ou igual a 0 (BUENOS et al., 2017).

O hidrograma da calibração (Figura 1A) e validação (Figura 1B) respondeu adequadamente a simulação realizada pelo modelo SWAT, obtendo valores mínimos e máximos das vazões diárias, apresentando resultados satisfatórios com $R^{2}$ igual a 0,86 e NS igual a 0,7 , no período de calibração e $R^{2}$ igual 
a 0,98 e NS igual a 0,9 no período de validação. Após os ajustes da validação, observou-se um padrão no comportamento dos picos e recessões do hidrograma, respeitando a sazonalidade do período analisado. Demonstrando que o modelo SWAT apresentou um bom desempenho.

(A)

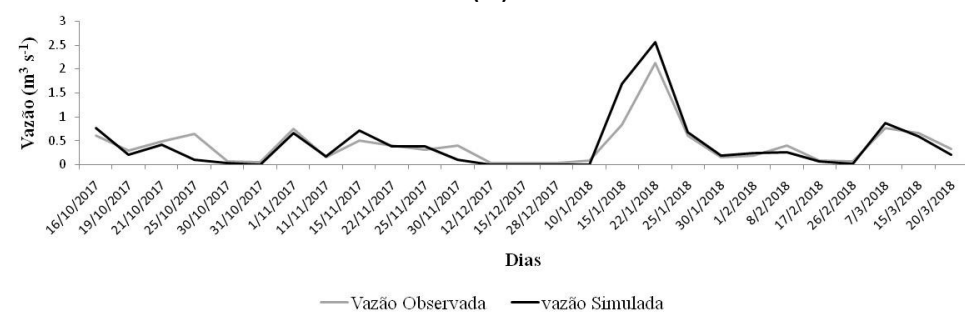

(B)

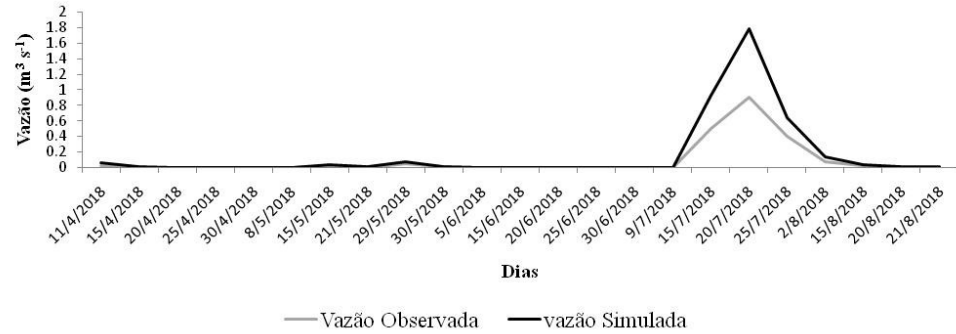

Figura 1: (A) Vazão no período de calibração e (B) Vazão no período de validação.

Estes resultados (simulações) são processados pelo SWAT (sub-bacias) e agrupados em Unidades de Resposta Hidrológica (URH's), que neste estudo, possui uma única combinação do tipo e uso do solo e classes de declividades, preservando a homogeneidade e permitindo maior discretização do modelo na área simulada (GALHARTE et al., 2013). Ainda, foi usada a opção de uso dominante, assim foram geradas 23 subbacias, totalizando 23 unidades de respostas. Após estes processos e em conjunto com as simulações o modelo simula diversas variáveis que compõem o balanço hídrico através da equação:

$$
\mathrm{SW}_{\mathrm{t}}=\mathrm{SW}_{0}+\sum_{\mathrm{i}=1}^{\mathrm{t}}(P R P-\mathrm{SURQ}-\mathrm{Et}-\mathrm{PERC}-\mathrm{QR}) \text { (1) }
$$

Onde: precipitação (PRP) (mm); evapotranspiração (Et) (mm); Escoamento superficial (SURQ) (mm); escoamento subterrâneo (GW_Q) (mm); quantidade de água no solo final e inicial ( $S W$ e $S W_{0}$, respectivamente) (mm); percolação (PERC) (mm), fluxo de retorno (QR) $(\mathrm{mm})$ (é o escoamento de água no interfluxo, sobre a superfície do terreno, após emergir da superfície, ocorrida através da ascensão capilar), o tempo (t) (dias) e produção de água total da sub-bacia que alcança o canal (WYLD) (mm). Maiores informações sobre o funcionamento do modelo SWAT podem ser obtidos em Neitsch et al. (2011) e Abbaspour (2015).

\section{Propagação do fluxo de água}

Segundo Arnold et al. (2009), o sistema hidrológico simulado pelo SWAT compreende quatro principais componentes: os reservatórios superficiais, os reservatórios subsuperficiais, os reservatórios subterrâneos (aquíferos rasos ou livres) e os reservatórios subterrâneos (aquífero profundo). A contribuição desses reservatórios para o escoamento no canal provém do escoamento lateral a partir do perfil de solo e do escoamento de retorno do aquífero raso. O volume que percola do reservatório subsuperficial através do perfil de solo representa a recarga do aquífero raso, enquanto a água que percola para o aquífero profundo não retorna para o sistema.

Segundo Neitsch et al. (2005) o cálculo da vazão e da velocidade do escoamento nos rios é feito com a utilização da equação de Manning (Equações 1 e 2). Já a propagação da água nos rios utiliza o método de 
Williams (método de acumulação variada) ou Muskingum, os quais se baseiam no modelo da onda cinemática e na equação da continuidade. Ainda segundo o autor, o modelo assume que os canais possuem formato trapezoidal com taludes cuja inclinação ocorre na proporção de 2:1 (horizontal: vertical), ou seja, igual a 0,5. 0 usuário pode informar ao modelo o comprimento, a largura e a profundidade do canal quando preenchido até o nível mais alto quando ainda não ocorre inundação para fora do canal, assim como o coeficiente de Manning e a declividade do canal ao longo do seu comprimento.

Quando o volume de água nos canais é maior do que o limite máximo que o canal suporta, a água empoça em volta do canal, inundando as margens. A área de inundação também apresenta formato trapezoidal, entretanto a inclinação dos taludes é menor. Por meio dos cálculos de área seccional de vazão no canal e perímetro molhado, o modelo calcula o raio hidráulico do canal para uma dada profundidade. Essas variáveis são necessárias para definir a vazão e a velocidade no canal, conforme a equação de Manning:

$$
\begin{array}{cl}
\text { Eq. 1: } & q_{c h}=\frac{A_{c h} \cdot R_{c h}^{2 / 3} \cdot s l p_{c h}^{1 / 2}}{n} \\
\text { Eq. 2: } & \quad v_{c}=\frac{R_{c h}^{2 / 3} \cdot s l p_{c h}^{1 / 2}}{n}
\end{array}
$$

Onde: $\mathrm{q}_{\mathrm{ch}}$ é a vazão no canal $\left(\mathrm{m}^{3} \cdot \mathrm{s}^{-1}\right)$; $\mathrm{A}_{c h}$ é a área seccional em que ocorre a vazão no canal $\left(\mathrm{m}^{2}\right) ; \mathrm{R}_{c h}$ é o raio hidráulico do canal para uma determinada profundidade $(\mathrm{m})$; $\mathrm{sl}$ ch é a declividade ao longo do comprimento do canal $\left(\mathrm{m} \cdot \mathrm{m}^{-1}\right) ; \mathrm{n}$ é o coeficiente ' $n$ ' de Manning para o canal; e $v_{c}$ é a velocidade do fluxo no canal (m.s-1).

Enquanto que, o método de acumulação variada proposto por Williams (1969), é baseado na equação da continuidade, o qual é expresso à propagação de água pelo canal (Equação 3):

$$
\text { Eq. 3: } \quad V_{\text {out }, 2}=S C \text {. }\left(V_{\text {in }}+V_{\text {stored }, 1}\right)
$$

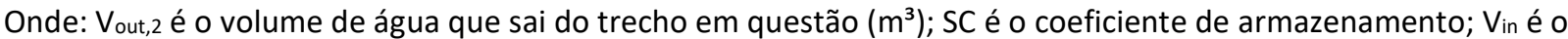
volume que entra no período em questão $\left(\mathrm{m}^{3}\right)$; e $\mathrm{V}_{\mathrm{stored}, 1}$ é o volume acumulado no início do período $\left(\mathrm{m}^{3}\right)$.

$O$ coeficiente de armazenamento é calculado pela equação 4:

Eq. 4:

$$
S C=\frac{2 . \Delta t}{2 . T T \cdot \Delta t}
$$

Onde: $\Delta$ t é o período de tempo (s); e TT é o tempo de viagem.

Outro fator que vale ressaltar é as perdas por transmissão, em que, durantes os períodos em que os canais não recebem contribuição de água subterrânea é possível que aconteçam perdas por transmissão no leito do rio. As perdas por transmissão são estimadas pela equação 5:

$$
\text { Eq. 5: } \quad \text { tloss }=K_{c h} \cdot T T \cdot P_{c h} \cdot L_{c h}
$$

Onde: tloss são as perdas por transmissão no canal $\left(\mathrm{m}^{3} \mathrm{H}_{2} \mathrm{O}\right), \mathrm{K}_{\mathrm{ch}}$ é a condutividade hidráulica do leito do rio $(\mathrm{mm} / \mathrm{h})$, TT é o tempo de viagem do fluxo $(\mathrm{h}), \mathrm{P}_{\mathrm{ch}}$ é o perímetro molhado $(\mathrm{m})$, Lch é o comprimento do canal $(\mathrm{Km})$. O parâmetro $\mathrm{K}_{\mathrm{ch}}$ é conhecido como $\mathrm{CH}-\mathrm{K} 2$ na calibração do SWAT.

Tabela 1: As referências de valores de Kc.

\begin{tabular}{|l|l|l|}
\hline Grupo & Características do leito & $\begin{array}{l}\text { Condutividade } \\
\text { Hidráulica }\end{array}$ \\
\hline Taxa de perda muito alta & Pedregulho limpo e areia grosseira & $127 \mathrm{~mm} \cdot \mathrm{h}^{-1}$ \\
\hline Taxa de perda alta & Areia e pedregulho limpo & $51-127 \mathrm{~mm} \cdot \mathrm{h}^{-1}$ \\
\hline Taxa de perda moderadamente alta & $\begin{array}{l}\text { Mistura de areia e pedregulho com baixo teor de material silto- } \\
\text { argiloso }\end{array}$ & $25 \mathrm{~mm} \cdot \mathrm{h}^{-1}$ \\
\hline Taxa de perda moderada & $\begin{array}{l}\text { Mistura de areia e pedregulho com alto teor de material silto- } \\
\text { argiloso }\end{array}$ & $6-25 \mathrm{~mm} \cdot \mathrm{h}^{-1}$ \\
\hline $\begin{array}{l}\text { Taxa de perda de baixa a } \\
\text { insignificante }\end{array}$ & $\begin{array}{l}\text { Leito de material consolidado alto teor de material silto-argiloso } \\
0,025-2,5 \mathrm{~mm} \cdot \mathrm{h}^{-1}\end{array}$ \\
\hline
\end{tabular}

Fonte: Neitsch et al. (2005). 


\section{Análise morfométrica}

Para a caracterização morfométrica da bacia do rio Apeú foi utilizado às metodologias propostas por Horton (1945), Strahler (1957), Christofoletti (1969), entre outros. Em que foi analisado o parâmetros relativos à área da bacia, o perímetro, a densidade da drenagem, o fator de forma, o coeficiente de compacidade, o índice de circularidade, a declividade média e a ordem hierárquica dos canais.

Segundo Tonello et al. (2006), as características morfométrica podem ser divididas em: características geométricas, características do relevo e características da rede de drenagem. Para a realização dos cálculos foi utilizado o software ArcGis 10.3 e as definições foram baseadas em Antoneli et al. (2007), Christofolletti (1969), Villela et al. (1975), Tonello et al. (2006) e Cardoso et al. (2006). A partir de estudos de Teodoro et al. (2007) e de Doriguel et al. (2015).

Características geométricas: Área total: Toda área drenada pelo sistema pluvial inclusa entre seus divisores topográficos, projetada em plano horizontal, sendo elemento básico para o cálculo de diversos índices morfométricos; Perímetro total: Comprimento da linha imaginária ao longo do divisor de águas; Coeficiente de compacidade (Kc): Relação entre o perímetro e a área da bacia, em que, se a bacia for irregular, maior será o coeficiente de compacidade e menos sujeita à enchentes, sendo: Kc entre 1-1,25 (redondas para ovaladas); e, entre 1,25-1,50 (ovaladas); entre 1,50-1,70 (longas); Fator de Forma (F): Relaciona a forma da bacia com a de um retângulo, correspondendo à razão entre a largura média e o comprimento axial da bacia (da foz ao ponto mais longínquo do espigão), podendo ser influenciada por algumas características, principalmente pela geologia; Índice de circularidade (IC): É a relação entre o perímetro e a área da bacia.

Características do relevo: Declividade: A declividade relaciona-se com a velocidade em que se dá o escoamento superficial, afetando, portanto, o tempo que leva a água da chuva para concentrar-se nos leitos fluviais que constituem a rede de drenagem das bacias, sendo que os picos de enchente, infiltração e susceptibilidade para erosão dos solos dependem da rapidez com que ocorre o escoamento sobre os terrenos da bacia; Altitude: A variação de altitude associa-se com a precipitação, evaporação e transpiração, consequentemente sobre o deflúvio médio; Amplitude: É a variação entre a altitude máxima e altitude mínima.

Características da rede de drenagem: Comprimento do curso d'água principal; Comprimento total dos cursos d'água; Densidade de drenagem (Dd): É a correlação do comprimento total dos rios com a área da bacia; Ordem dos cursos d'água: A classificação dos rios quanto à ordem reflete no grau de ramificação ou bifurcação dentro de uma bacia.

\section{RESULTADOS E DISCUSSÃO}

Ao representar o caminho que água percorre na bacia hidrográfica, onde a precipitação é a principal entrada, a qual propicia os divisores de água que limitam e definem o fluxo hídrico e permite o estabelecimento de um padrão de drenagem, passível de ser identificado, quantificado, classificado e caracterizado (SOUSA et al., 2016). Na bacia do rio Apeú, a precipitação apresentou uma distribuição 
uniforme considerada igual por toda bacia. Em que é perceptível na figura 2, que os anos com maiores volumes de precipitação aconteceram entre 2008 e 2010, enquanto que os anosentre 2012 e 2014 apresentaram menores valores. Podendo está relacionado com a variabilidade climática locais.

Segundo Menezes et al. (2015) a distribuição da precipitação pluviométrica sobre o estado do Pará é caracterizada pela altavariabilidade espacial e temporal, e as precipitações são predominantemente do tipo convectivas, e constitui um dos elementos climáticos de maior importância para o condicionamento social e econômico em todos os estágios de desenvolvimento. $\mathrm{E}$ isso está relacionado com o fato das precipitações anuais na Amazônia Oriental, onde está localizado a área em estudo tender a decrescer do setor costeiro para o interior, decorrente da forma como se originam os sistemas de circulação ao penetrarem a região. Assim, fenômenos de escala planetária como a Zona de Convergência Intertropical (ZCIT), e fenômenos de mesoescala como as Linhas de Instabilidade (LIs), têm grande influência na climatologia da precipitação desta região.

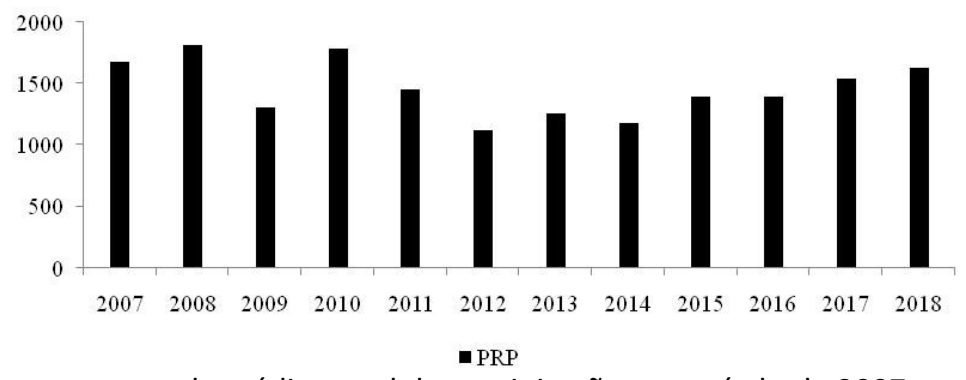

Figura 2: Comportamento da média anual da precipitação no período de 2007 a agosto de 2018.

A precipitação após seu contato com o solo, parte dela é escoada, outra é infiltrada e/ou percolada, dependendo das características físicas da bacia. Estudos como o de Lorenzon et al. (2015), Luz et al. (2015) e Pinheiro et al. (2018) demonstram que as características físicas de uma bacia influenciam diretamente no caminho da água percorrido. Nesse sentido, a bacia do rio Apeú apresenta em sua composição, $41 \%$ de áreas antrópicas agrícolas, 35\% de floresta mista (primária e secundária), 12\% de área urbana, 11\% de pastagem e apenas $1 \%$ compõem a mineração e os corpos hídricos. Vale destacar que a bacia possui apenas $35 \%$ de as áreas compostas por floresta, em contrapartida com $65 \%$ do resto de sua área é considerada impermeabilizada.

Hoffmann et al. (2017) identificaram em pesquisas parecidas aplicadas em uma bacia hidrográfica em Santa Catarina, que através dos diversos uso e cobertura do solo, foi perceptível que a floresta permite uma melhor infiltração da água nos solos, favorecendo o escoamento subsuperficial e subterrâneo, diferente do comportamento da água em outros tipos de usos do solo, como o caso da área urbana, que demonstrou desempenho ao contrário do que na floresta.

Benini et al. (2017) mostraram que ocupações próximas as áreas de drenagem são apenas parte de um problema das dinâmicas fluviais, pois as "alterações decorrentes do uso do solo, como a retirada da vegetação e a impermeabilização do solo, causam um dos impactos humanos mais significativos no ciclo hidrológico", como por exemplo, os problemas de drenagem urbana - inundação.

Quando associados ao tipo de solo presentes na bacia (92\% de Latossolo Amarelo e 8\% de Gleissolo 
Háplico) é percebido que apesar de, em quase sua totalidade a bacia do rio Apeú ser composta por Latossolo Amarelo, sendo considerado um solo com perfil muito homogêneo e de boa drenagem, ainda sim gera escoamento superficial quando associados ao uso do solo da bacia, e também por estar próximo ao Gleissolo háplico, devido este tipo de solo ser considerado de má drenagem, o qual está localizado próximo ao seu exutório.

Outro fator influenciador do escoamento da água na bacia hidrográfica são as características morfométrica, em que, ao calcular às características da bacia do rio Apeú, foi possível obter como resultado uma área de drenagem total de $307 \mathrm{~km}^{2}$, cujo perímetro calculado foi de 132,16 km e o fluxo de água se dá na direção N-SE da bacia. O comprimento total da rede de drenagem é de $173 \mathrm{~km}$, possuindo 33 canais, o que demonstra que a baciaé ramificada, e bem distribuída podendo ser caracterizada como uma bacia de 3 a ordem (STRAHLER, 1957).

O baixo valor do fator de forma $(0,59)$ obtido para o rio Apeú indica que ela possui um formato mais alongado, permitindo interpretar a ocorrência de um número significativo de tributários atingindo o rio principal, sobretudo no médio e alto curso, aumentandoa taxa de escoamento superficial no baixo curso e consequentemente ocasionando áreas alagadas no baixo curso durante a maior parte do ano (SOUSA et al., 2016).

O fator deforma é um importante parâmetro para a determinação do tempo de concentração, que indica o tempo necessário para a contribuição de água da baciaapós um evento de precipitação, assim quanto maior este tempo menor será a vazão máxima (CAMPOS et al., 2015). O Índice de circularidade $(0,22)$ e o coeficiente de compacidade $(2,11)$ também evidenciam que a bacia do rio Apeú possui uma formaalongada e segundo os estudos realizados por Doriguel et al. (2015) mostram que valores do IC menor que 0,51, a bacia é mais alongada favorecendo desta forma a infiltração, aumentando o tempo de concentração nasub-bacia.

A densidade de drenagem obtida foi de $0,5 \mathrm{~km} / \mathrm{km}^{2}$, podendo afirmar que ela é uma bacia com drenagem pobre (VILLELA et al., 1975), demonstrando que a bacia do rio Apeú é apresenta baixa drenagem, apesar de apresentar um número considerável de ramificações de rede de drenagem (33 canais). A declividade média encontrada da bacia foi de $1,9 \%$, sendo classificada com um relevo plano, segundo a Embrapa (2006) que considera superfícies com declividade entre 0 e 3\%, apresentando terrenos com topografia horizontal, com poucos desnivelamentos.

Nesse sentido, o modelo SWAT foi capaz de determinar o movimento de água precipitada na bacia do rio Apeú, através da simulação do balanço hídrico (SABZEVARI et al., 2010), obtendo como resposta a quantidade total de água que entra no canal principal (rendimento de água - WYLD), através dos afluentes, durante o período em estudo, bem como as perdas de água (TLOSS) através da evapotranspiração (evaporação da água e transpiração das plantas).

Ao analisar essa simulação (Figura 3) é perceptível que em 2008 foi o ano em que a bacia hidrográfica do rio Apeú apresentou maior média de produção de água propagada $(129,06 \mathrm{~mm})$ e coincidentemente a menor perda (22,44 mm), com uma precipitação de $152 \mathrm{~mm}$, enquanto que o ano que apresentou menor volume $(46,79)$ foi de o ano de 2014 , com uma perda de $51,88 \mathrm{~mm}$, com um total de precipitação de $99 \mathrm{~mm}$. 
Contudo, os anos de 2012 a 2014 obtiveram precipitações baixas, não ultrapassando 110 mm, em que a bacia hidrográfica do rio Apeú apresentou um rendimento de menos que $50 \%$ de WYLD, obtendo uma alta perda de volume de água por evapotranspiração e evaporação. Enquanto que, ao ano de 2017 e até o mês de agosto de 2018, o WYLD e o TLOSS se mantiveram em equilíbrio.

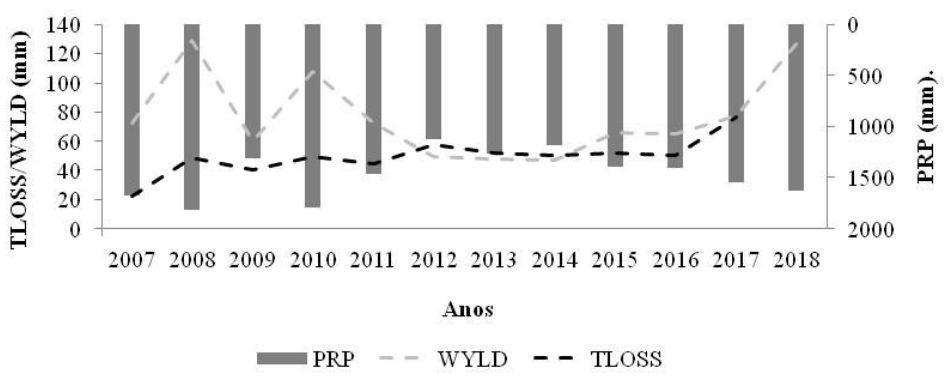

Figura 3: Gráficos do comportamento da produção e perdas de águas no período de 2007 a 2018.

Essa variação da quantidade produzida e a quantidade perdida de água na bacia do rio Apeú, têm diversos motivos, sendo primeiramente uma resposta das chuvas, que entram na bacia, como vimos anteriormente, mas a sua permanência é influenciada pelo uso e ocupação do solo no seu entorno. Em que, esta influência pode ser comprovada no estudo de Santos et al. (2010) que verificaram o comportamento hidrológico associada à variabilidade climática e ao uso do solo, ao longo de 25 anos, na bacia hidrográfica do Ribeirão João Leite, em Goiânia, onde constataram que as alterações no uso do solo influenciaram no escoamento da água, mesmo no período de redução das chuvas, causando um aumento de WYLD na bacia.

Locais que ainda mantém a mata ciliar preservada tendem um aumento na quantidade de WYLD, pois oferecem uma maior taxa de infiltração da água no solo e consequentemente um aumento na alimentação dos lençóis freáticos, proporcionando um regime sustentável na produção hídrica, enquanto áreas sem a proteção (área urbana, pasto, áreas agrícolas e mineradoras) provocam escoamentos superficiais intensos, erosões e podendo provocar ainda nos períodos de estiagem, a diminuição do corpo d'água decorrente dos déficits hídricos podendo até seca (SOUSA et al., 2016).

Isso é mais bem visualizado quando espacializados por sub-bacias geradas pelo modelo, onde é possível ver a distribuição temporal que cada sub-bacia contribui com o rio principal, nos anos de 2007 a agosto de 2018 (Figura 4B e 4C). Além de como está distribuída a drenagem no espaço e a localização das nascentes (Figura 4A). Em que foi possível confirmar que o ano de maior produção foi o de 2008 e os de menor produção foi o ano de 2014. Contudo, é perceptível que os outros anos há uma variação de contribuição por sub-bacias, onde a bacia de número 4 é a que menos contribuiu em todos os anos (Figura 4).

De acordo, com o anuário estatístico do Pará (FAPESPA, 2016), houve um aumento de $20 \%$ na demografia do município de Castanhal, em 2008 o município apresentava uma população de 155,26 habitantes por km², já em 2016, esta população saltou para 187,16 habitantes por km². Somada ao aumento populacional, ocorreu também o aumento das áreas desmatadas que em 2008 eram de 898 km², já em 2017 estas áreasforam de 905,8 km², ocasionando a perda de $4 \%$ nas áreas de floresta na bacia (PRODES, 2018).

Estes aumentos demonstraram uma relação direta com a expansão da pecuária na região, que desde 
2008 vem aumentando, chegando a uma expansão de 10 \% no município. Houve também um aumento da infraestrutura da região, o censo de 2010 apontou que 36,1 \% da região receberam esgotamento sanitário, $16,9 \%$ das ruas eram arborizadas e 13,9\% domunicípio estavam urbanizados, um aumento de $15 \%$ quando comparado a 2008 (IBGE, 2018).

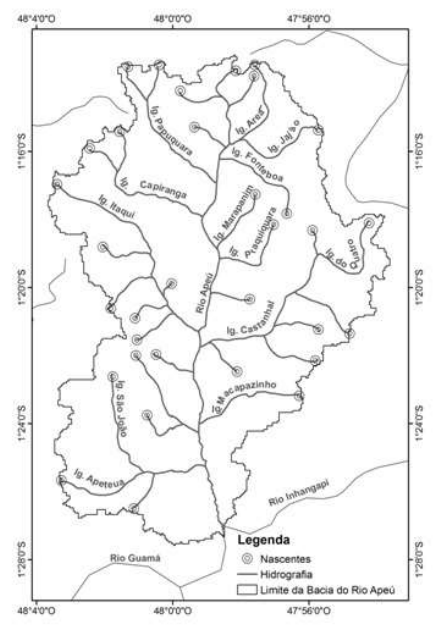

A - Definição da drenagem da bacia do Rio Apeú
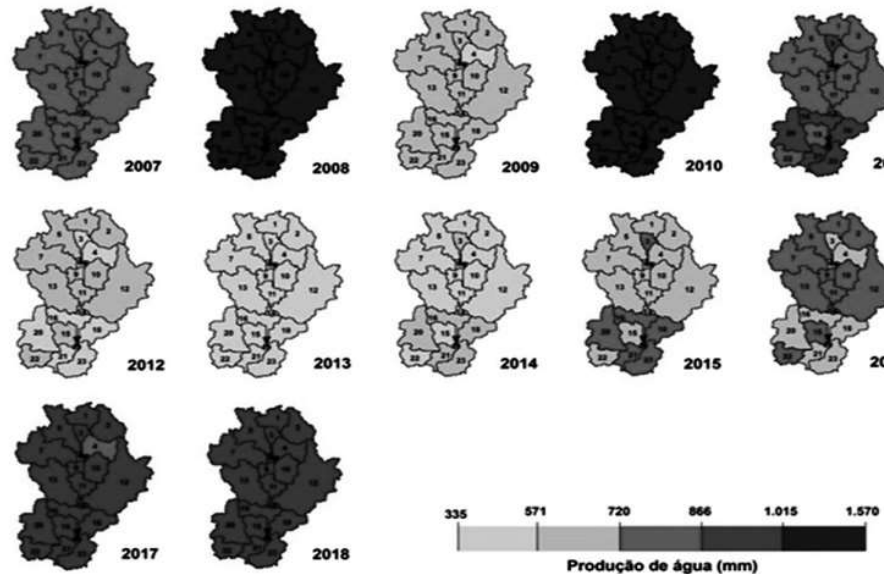

C - Espacialização da Produção de água (WYLD) da bacia do rio Apeú.

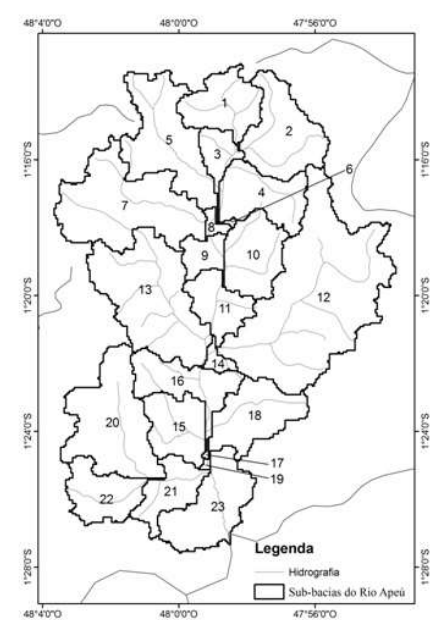

B - Sub-bacias geradas pelo modelo SWAT
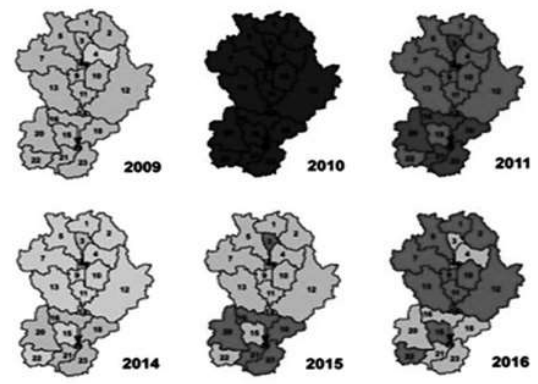

Figura 4: Espacialização dos cursos produção de água na bacia do rio Apeú.

As formas como a população usufruem dos recursos hídricos interferem diretamente na quantidade e qualidade das águas. Na bacia do rio Apeú as diversas formas de uso do solo tem influenciado nas suas características físicas, podendo interferir em todo sistema, segundo Zanata et al. (2015), a bacia é um sistema aberto, onde o fluxo de matéria e energia é dinâmico e altamente dependente da gestão dos solos.

Vale ressaltar que a vegetação ao longo dos afluentes do rio Apeú possui um papel fundamental na vida útil da bacia, entretanto observa-se no local que grandes extensões não cumprem a proteção prevista pela legislação, onde é agravada pelas ações ilegais de desrespeito ao Código Florestal brasileiro, no que concerne à manutenção da floresta natural ao longo dos rios e nascentes, como também a falta de fiscalização e dificuldades na recuperação destas áreas (ALMEIDA et al., 2014).

Estudos, como os de Vale et al. (2015) comprovam que o maior agente transformador da paisagem na área da bacia hidrográfica do rio Apeú é a ação antrópica, em virtude das atividades econômicas que 
foram estabelecidas ao longo dos anos. A paisagem predominante na área é a de pastagem, em seguida se têm as áreas remanescentes de vegetação e as áreas de plena expansão urbana. A vegetação de tipologia arbórea da bacia hidrográfica do rio Apeú se encontra bastante fragmentada, caracterizada pela presença de um grande número de fragmentos pequenos, demonstrando o forte impacto da atividade humana na área.

\section{CONCLUSÕES}

A bacia do rio Apeú, em geral, encontra-se em um nível de produção de água considerado normal apesar das diferentes influências no entorno de suas nascentes, o grau de degradação é considerado estável no período estudado, sendo coerente com as quantidades de chuvas na região, bem como, a simulação do modelo, que foi de forma coerente na sua distribuição.

Cada sub-bacia em que o modelo subdividiu possui áreas diferentes, variando de $0,18 \mathrm{~km}^{2}$ (sub-bacia 17) a $56 \mathrm{Km}^{2}$ (sub-bacia 12), não ultrapassando $100 \mathrm{~km}^{2}$, uma vez que áreas maiores do que esses valores podem sofrer efeitos de escala, ou seja, diferentes usos e tipos de solos, alterações atmosféricas, diferenças na rede de drenagem, resultando em processos hidrológicos com comportamentos distintos.

A diminuição da produção de água na bacia hidrográfica do rio Apeú está intimamente ligada às alterações ocorridas ao longo dos anos na bacia, isto demonstra que além de ser um indicador de alterações pode auxiliar no gerenciamento ambiental, apontando alterações nos cursos d'águas e nas suas nascentes, modificando a sua forma e consequentemente afetando a produtividade econômica, a segurança social e ambiental da população local.

A produção de água na bacia, desde 2008 vem diminuindo em até 60\%, decorrente das transformações ocorridas no seu entorno. Dada principalmente pela influência antrópica que promoveu grandes alterações na dinâmica natural do rio diminuindo sua capacidade de produção. Nesse sentido, a bacia do rio Apeú mostrou que o processo de uso e ocupação nas suas proximidades influencia diretamente na produção de água da mesma, necessitando de medidas que tendem promover a sua recuperação, para que os afluentes e nascentes sejam preservados, e com isso manter a contribuição de água em direção ao rio Inhangapi.

\section{REFERÊNCIAS}

ABBASPOUR, K. C.. SWAT-CUP: SWAT Calibration and Uncertainty Programs-A User Manual. Dübendorf: EAWAG, 2015.

ABREU, M. C.; TONELLO, K. C.. Estimativa do balanço hídrico climatológico da bacia hidrográfica do rio Sorocaba, São Paulo. Ambiência, Guarapuava, v.11, n.3, 2015.

ADAM, K. N.; FAN, F. M.; PONTES, P. R.; BRAVO, J. M.; COLLISCHONN, W.. Mudanças Climáticas e Vazões Extremas na Bacia do Rio Paraná. RBRH, Porto Alegre, v.20, n.4, p.9991007, 2015

ALMEIDA, C. A.; COUTINHO, A. C.; ESQUERDO, J. C. D. M. ADAMI, M.; VENTURIERI, A.; DINIZ, C. G.; DESSAY, N.; DURIEUX, L.; GOMES, A. R.. High spatial resolution land use and land cover mapping of the Brazilian Legal Amazon in 2008 using Landsat-5/TM and MODIS data. Acta Amazônica, v.46, n.3, p.291-302, 2016.

ALMEIDA, L.; SERRA, J. C. V.. Modelos hidrológicos, tipos e aplicações mais utilizadas. Revista da FAE, v.20, n.1, 2017.

ALMEIDA, A. S.; VIEIRA, I. C. G.. Conflitos no uso da terra em Áreas de Preservação Permanente em um polo de produção de biodiesel no Estado do Pará. Revista Ambiente \& Água, p.484-485, 2014

ANTONELI, V.; THOMAZ, E. L.. Caracterização do meio físico da bacia do Arroio Boa Vista, Guamiranga/PR. Rev. Caminhos da Geografia, Uberlândia, v.8, n.21, p.46-58, 2007. 
ARNOLD, J. G. J. R.; WILLIAMS, R.; SRINIVASAN, K. K. W.. SWAT: Soil and Water Assessment Tool. Temple: USDA-ARS, Grassland, Soil and Water Research Laboratory, 1998.

ARNOLD, J. G.; FOHRER, N.. SWAT2000: current capabilities and research opportunities in applied watershed modelling. Hydrological processes, v.19, n.3, 2005.

ARNOLD, J. G.; MORIASI, D. N.; GASSMAN, P. W.; ABBASPOUR, K. C.; WHITE, M. J.; SRINIVASAN, R.; SANTHI, C.; HARMEL, R. D.; VAN GRIENSVEN, A.; VAN LIEW, M. W.; KANNAN, N.; JHA, M. K.. SWAT: Model Use, Calibration, and Validation. Transactions of the ASABE, v.55, n.4, p.14911508,2012

ARNOLD, J. G.; KINIRY, J. R.; SRINIVASAN, R.; WILLIAMS, J. R.; NEITSCH, S. L.. Soil and water assessment tool: input/output file documentation. Temple: Soil And Water Research Laboratory \& Blackland Research Center, 2009.

BARRY, G. R.; CHORLEY, R. J.. Atmosfera, Tempo e Clima. Porto Alegre: Bookman, 2013.

BARROS, A. B.; BARROS, A. M. A.. A difícil aplicabilidade da política de águas no Brasil. Inter Science Place, v.7, n.2, p.121, 2009.

BLAINSKI, É.; ACOSTA, E.; NOGUEIRA, P. C. P.. Calibração e validação do modelo SWAT para simulação hidrológica em uma bacia hidrográfica do litoral norte catarinense. Rev. Ambient. Água, Taubaté, v.12 n.2, p.226-237, 2017.

BENINI, S. M.; ROSIN, J. A. R. G.. Dinâmica fluvial no espaço urbano: aspectos relevantes. Revista Nacional de Gerenciamento de Cidades, v.5, n.31, p.54-67, 2017.

BRESSIANI, D. A.; GASSMAN, P. W.; FERNANDES, J. G.; GARBOSSA, L. H. P.; SRINIVASAN, R.; BONUMA, N. B.; MENDIONDO, E. M.. Review of soil and water assessment tool (SWAT) applications in Brazil: challenges and prospects. International Journal of Agricultural and Biological Engineering, Beijing, v.8, n.3, p.9-35, 2015.

BUENO, E. O.; OLIVEIRA, V. A.; VIOLA, M. R.; MELLO, C. R.. Desempenho do Modelo SWAT para Diferentes Critérios de Geração de Unidades de Resposta Hidrológica. Revista Scientia Agrária, Curitiba, v.18 n.2, p.114-125, 2017.

CAMPOS, S.; FELIPE, A. C.; CAMPOS, M.; RECHE, A. M Geoprocessamento Aplicado na Caracterização Morfométricas da Micro bacia do Ribeirão Descalvado, Botucatu/SP. Irriga, v.1, n.1, p.52-65, 2015.

CARDOSO, C. A.; DIAS, H. C. T.; SOARES, C. P. B.; MARTINS, S. V.. Caracterização morfométrica da bacia hidrográfica do rio Debossan, Nova Friburgo/RJ. Árvore, Viçosa, v.30, n.2, p.241-248, 2006.

CORREIA, E. F. G.; RIBEIRO, G. P.; BAPTISTA, A. C.. Bengalas, Nova Friburgo, RJ, Utilizando o Potencial de Geotecnologias na Definição de Áreas de Risco à Inundação. Revista Brasileira de Cartografia, v.67, n.6, p.1183-1202, 2015.

COUTINHO, A. C.; ALMEIDA, C.; VENTURIERI, A.; ESQUERDO, J. C. D. M.; SILVA, M.. Uso e cobertura da terra nas áreas desflorestadas da Amazônia Legal TerraClass 2008. Brasília:
EMBRAPA, 2013

CHRISTOFOLETTI, A.. Análise morfométrica de bacias hidrográficas. Notícia Geomorfológica, n.18, p.35-64, 1969.

CRUZ, J. C.; TUCCI, C. E. M.. Estimativa da Disponibilidade Hídrica Através da Curva de Permanência. RBRH Revista Brasileira de Recursos Hídricos, v.13, n.1, p.80-87, 2008

DORIGUEL, F.; CAMPOS, S.; DELMANTO JUNIOR, O.. Caracterização Morfométrica da Microbacia do Córrego Maria Pires, Santa Maria da Serra, Estado de São Paulo. Brasil. Energ. Agric, Botucatu, v.30, n.4, p.372-377, 2015.

EMBRAPA. Empresa Brasileira de Pesquisa Agropecuária. Sistema brasileiro de classificação de solos. 2 ed. Brasília: Embrapa Produção de Informação, 2006.

FAPESPA. Fundação Amazônia de Amparo a Estudos e Pesquisas do Pará. Estatísticas municipais paraenses. Belém: FAPESPA, 2016.

GALHARTE, C. A.; VILLELA, J. M.; CRESTANA, S.. Estimativa da Produção de Sedimentos em Função da Mudança de Uso e Cobertura do Solo. R. Bras. Eng. Agríc. Ambiental, v.18, n.2, p.194-201, 2013.

GASSMAN, P. W.; REYES, M. R.; GREEN, C. H.; ARNOLD, J. G. The soil and water assessment tool: historical development, applications, and future research directions. Transactions of the ASABE, St. Joseph, v.50, n.4, p.1211-1250, 2007.

HOFFMANN, G. P.; NANNI, A. S.. O uso da terra e sua influência sobre o volume das águas na Bacia do Rio Biguaçu/SC. Geosul, v.32, n.63, p.97-117, 2017.

HORTON, R. E.. Erosional development of streams and their drainage basins: hidrophysical approach to quantitative morphology. Geological Society of America Bulletin, v.56, p.807-813, 1945.

IBGE. Instituto Brasileiro De Geografia Estatística. Censo 2010. Brasília: IBGE, 2010

INPE. Instituto Nacional de Pesquisas Espaciais. Banco de dados do projeto Programa de Monitoramento da Amazônia por Satélite PRODES. Brasília: INPE, 2010.

LORENZON, A. S.; DIAS, H. C. T.; TONELLO, K. C.. Escoamento Superficial da Água da Chuva em um Fragmento Florestal de Mata Atlântica, Viçosa/MG. Revista Brasileira de Agropecuária Sustentável, v.5, n.1, p.50-58, 2015.

LUZ, T. E.; LIMA, E. B. N. R.; SALOMÃO, F. X. T.; LIMA, Z. M.. Morfopedologia Aplicada à Concepção de Obras em Microbacia do Perímetro Urbano de Várzea Grande/MT. Rev. Ambient. Água, Taubaté, v.10 n.3, p.646-659, 2015.

MALDONADO, L. H.; WENDLAND, E. C.; PORTO, M. P.. Avaliação de Métodos de Baixo Custo para Medição de Vazão em Córregos. Ambiente \& Água, v.10, n.2, p.402-412, 2015.

MARINHO FILHO, G. M.; ANDRADE, R. S.; ZUOWSI JUNIOR, J. C.; MAGALHÃES FILHO, L. N. L.. Modelos Hidrológicos: conceitos e aplicabilidades. Revista de Ciências Ambientais, Canoas, v.6, n.2, p.35-47, 2012 
MENEZES, F. P.; FERNANDES, L. L.; ROCHA, E. J. P.. O Uso da Estatística para Regionalização da Precipitação no Estado do Pará, Brasil. Revista Brasileira de Climatologia, v.11, n.16, p.64-71, 2015.

MONTAÑO, M.; SOUZA, M. P.. Integração entre Planejamento do Uso do Solo e de Recursos Hídricos: a disponibilidade hídrica como critério para a localização de empreendimentos. Revista de Eng. Sanit. Ambient., v.21, n.3, p.489-495, 2016

MORIASI, D. N.; GITAU, M. W.; PAI, N.; DAGGUPATI, P.. Hydrologic and water quality models: Performance measures and evaluation criteria. Transactions of the ASABE, v.58, n.6, p.1763-1785, 2015.

NASH, J. E.; SUTCLIFFE, J. V.. River Flow Forecasting Through Conceptual Models Part I: A discussion of Principles. Journal of Hydrology, v.10, n.3-4, p.282-290, 1970.

NEITSCH, S. L.; ARNOLD, J. G.; KINIRY, J. R.; WILLIAMS, J. R.. Soil and Water Assessment Tool Theoretical Documentation, Versão 2005. Temple: Blackland Research Center, Texas Agricultural Experiment Station, 2005.

NEITSCH, S. L.; ARNOLD, J. G.; KINIRY, J. R.; WILLIAMS, J. R.. Soil and Water Assessment Tool Theoretical Documentation, Versão 2009. Temple: Blackland Research Center, Texas Agricultural Experiment Station, 2009.

NEITSCH, S. L.; ARNOLD, J. G.; KINIRY, J. R.; WILLIAMS, J. R. Soil and Water Assessment Tool Theoretical Documentation Version 2009: TR-406. Temple: Water Resources Institute, College Station, 2011.

OLIVEIRA, F. M.; NUNES, T.. Aplicação de protocolo de avaliação rápida para caracterização da qualidade ambiental do manancial de captação (Rio Pequeno) do município de Linhares/ES. Natureza, v.13, n.2, p.86-91, 2015.

PANIZZA, A. C.. A importância da Mata ciliar: Entenda por que as formações vegetais ciliares são essenciais para os ecossistemas e para os recursos hídricos. São Paulo, 2016.

PERAZZOLI, M.; PINHEIRO, A.; KAUFMANN, V.. Efeitos de cenários de uso do solo sobre o regime hídrico e produção de sedimentos na bacia do Ribeirão Concórdia/SC. Revista Árvore, Viçosa, v.37, n.5, p.859-869, 2013.

PINHEIRO, A. G.; SANTOS, J. C. N.; PALÁCIO, H. A. Q.; ARAÚJO NETO, J. R.; ANDRADE, E. M.. Eficiência da Cobertura Vegetal na Redução das Perdas de Água e Solo no Município de Iguatu. Irriga, Botucatu, v.23, n.1, p.133-142, 2018.

PORTO, M. F. A.; PORTO, R. L. L.. Gestão de Bacias Hidrográficas. Estudos Avançados, São Paulo, v.22, n.63, p.43-60, 2008.

RODRIGUES, S. A.; BATISTELA, G. C.. Uma Revisão sobre a Disponibilidade Hídrica Brasileira para Geração de Energia Elétrica?. Geoambiente, Jataí, n.21, 2013.

SABZEVARI, T.; ARDAKANIAN, R.; TALEBI, A.; SHAMSAI, A.. Watersheds Flood Forecasting using HEC-GeoHMS and HECHMS Model. In: INTERNATIONAL CONFERENCE ON ENVIRONMENTAL SCIENCE AND DEVELOPMENT. Anais,
2010. p.323-327.

SANTOS, G. V.; DIAS, H. C. T.; SILVA, A. P. S.;MACEDO, M. N. C.. Análise Hidrológica e Socioambiental da Bacia Hidrográfica do Córrego Romãodos Reis, Viçosa/MG. Revista Árvore, v.31, n.5, p.931-940, 2007.

SANTOS, E. H. M.; GRIEBELER, N. P.; OLIVEIRA, L. F. C.. Relação entre uso do solo e comportamento hidrológico na Bacia Hidrográfica do Ribeirão João Leite. Revista Brasileira de Engenharia Agrícola e Ambiental, v.14, n.8, p.826-834, 2010.

SANTOS, J. T. S.; NUNES, H. G. G. C.; PONTES, A. K. S.; SOUSA, A. M. L.. O Modelo SWAT como ferramenta para a gestão de recursos hídricos: Um exemplo aplicado no rio Apeú, Castanhal/PA. REGA, Porto Alegre, v.15, n.3, p.1-13, 2018

SILVA, N. D. M.; CHRISTOFARO, C.. Calibração do modelo hidrológico SWAT para estimativa da vazão em sub-bacia hidrográfica do Rio Jequitinhonha. In: SIMPÓSIO MODELAGEM DE SISTEMAS AMBIENTAIS E GESTÃO DA PAISAGEM: DESAFIOS E APLICAÇÕES, 2. Anais. 2017.

SOUZA, P. J. O. P.; FARIAS, V. D. S.; LIMA, M. J. A.; RAMOS, T. F.; SOUSA, A. M. L.. Produção de Área Foliar e Biomassa e Produtividade do Feijão-caupi sob Regimes Hídricos em Castanhal, Pará. Revista Caatinga, v.30, n.3, p.748-759, 2017.

SOUSA, R. C.; RIZZI, N. E.; RANZINI, M.; ARCOVA, F. C. S.; CICCO, V.; SILVA, L. R.. Interceptação pluviométrica pelo dossel de floresta ombrófila mista alto-montana no parque estadual de campos do Jordão, SP, Brasil. Floresta, v.46, n.2, p.243-250, 2016

STRAHLER, A. N.. Quantitative Analysis of Watershed Geomorphology. Transactions, American Geophysical Union, Washington, v.38, n.6, p.913-920, 1957.

TEODORO, V. L. I.; TEIXEIRA, D.; COSTA, D. J. L.; FULLER, B. B.. $O$ conceito de bacia hidrográfica e a importância da caracterização morfométrica para oentendimento da dinâmica ambiental local. Revista Uniara, n.20, p.137-157, 2007.

TESHAGER, A. D.; GASSMAN, P. W.; SECCHI, S.; SCHOOF, J. T.; MISGNA, G.. Modeling Agricultural Watersheds with the Soil and Water Assessment Tool (SWAT): Calibration and validation with a novel procedure for spatially explicit hrus. Environmental management, v.57, n.4, 2016.

TONELLO, K. C.; TEIXEIRA, H. C.; SOUZA, A. L.; RIBEIRO, A. S. R.; LEITE, F. L.. Morfometria da bacia hidrográfica da cachoeira das pombas, Ganhães/MG. Revista Árvore, Viçosa, v.30, n.5, p.849-857, 2006.

TUCCI, C. E. M.. Hidrologia: ciência e aplicação. 4 Ed. Porto Alegre: UFRGS, 2009.

USACE. US Army Corps of Engineers. HE-CRAS River Analysis System: Reference Manual. Hydrologic. Davis: Engineering Center, 2010.

VALE, J. R. B.; BORDALO, C. A. L.; FONSECA, L. C. N.. Análise do uso e cobertura da terra na bacia hidrográfica do Rio Apeú, nordeste paraense, entre os anos de 1999 e 
2014. Revista do Instituto Histórico e Geográfico do Pará,

v.2, n.2, p.22-34, 2016

VARGAS J. R. A.; JÚNIOR, P. D. F.. Aplicação de um Protocolo de Avaliação Rápida na Caracterização da Qualidade Ambiental de Duas Micro bacias do Rio Guandu, Afonso Cláudio/ES. Revista Brasileira de Recursos Hídricos, v.11, n.2, p.161-168. 2012.

VILLELA, S. M.; MATTOS, A.. Hidrologia aplicada. São Paulo: McGraw-Hill, 1975.
WINCHELL, M.; SRINIVASAN, R.; LUZIO, M.; ARNOLD, J.. ArcSWAT Interface for SWAT 2012: User's Guide. Blackland Research and Extension Center. Grassland, Soil and Water Research Laboratory, 2013.

ZANATA, M.; PISSARRA, T. C. T.; FERRAUDO, A. S.; RANZINI, M.; CAMPOS, S.. Effect of soil use on the quality of water resource in watershed using multivariate statistical analysis. Irriga, v.20, n.4, p.776, 2015

A CBPC - Companhia Brasileira de Produção Científica (CNPJ: 11.221.422/0001-03) detém os direitos materiais desta publicação. Os direitos referem-se à publicação do trabalho em qualquer parte do mundo, incluindo os direitos às renovações, expansões e disseminações da contribuição, bem como outros direitos subsidiários. Todos os trabalhos publicados eletronicamente poderão posteriormente ser publicados em coletâneas impressas sob coordenação da Sustenere Publishing, da Companhia Brasileira de Produção Científica e seus parceiros autorizados. Os (as) autores (as) preservam os direitos autorais, mas não têm permissão para a publicação da contribuição em outro meio, impresso ou digital, em português ou em tradução. 